\title{
Status of Groundwater in Jeju Volcanic Island, South Korea: Evaluation of Long-term Monitoring Data for Sustainable Mangagement
}

\author{
HYUN-Ji KANG ${ }^{1}$, HO-RIM KIM ${ }^{2}$, IK-HYUN HYUN ${ }^{3}$, \\ SANG-SIL OH ${ }^{3}$, SEONG-TAEK YUN ${ }^{1 *}$ \\ ${ }^{1}$ Department of Earth and Environmental Sciences, Korea \\ University, Seoul, South Korea (*correspondence: \\ styun@korea.ac.kr) \\ ${ }^{2}$ Korea Institute of Geoscience and Mineral Resources, \\ Daejeon, South Korea \\ ${ }^{3}$ Institute of Environmental Research, Jeju Special Self- \\ Governing Province, South Korea
}

Though the groundwater is a unique drinking water source in the Jeju volcanic island of South Korea, various environmental problems have been raised in recent years, impeding the sustainable management of groundwater. The supply-demand imbalance on water resources has been aggravated due to the growing population and the intensified urbanization. An increase in rainfall and a decrease in raining days also makes the recharge control difficult. Progressively increasing pollutant loadings like an illegal discharge of manure wastewater, and excessive usage of $\mathrm{N}$-fertilizer threatens the aquifer quality. Therefore, well understanding of groundwater vulnerability is crucial in long-term policymaking. For this task, we evaluated regional groundwater monitoring data that were collected from 209 public wells for the last 10 years (2009 2018). Sampling was conducted at least three or four times per year; the dataset consists of field parameters, major ions, and trace elements. Multivariate statistical analysis were used to identify major hydrochemical processes. The results of K-means clustering of groundwater samples suggest the occurrence of three distinct hydrochemical groups. The characteristics of each group are also understood through factor analysis. The first group mostly consists of recharge water with the lowest TDS. Samples in the second group show high $\mathrm{pH}$ and $\mathrm{Na}, \mathrm{K}$, $\mathrm{HCO}_{3}^{-}, \mathrm{V}$ concentrations, indicating their chemical controls by natural water-rock interaction. The last group shows high levels of EC and major ions, including $\mathrm{Na} \mathrm{NO}_{3}^{-}$, and $\mathrm{Cl}^{-}$, which suggests the varying degrees of anthropogenic pollution. Increasing agro-livestock activities and sea-water intrusion are the main sources of contamination, which are respectively dominant in the western and eastern watershed. The influences of spatio-temporal and socio-economic parameters on groundwater quality are also evaluated in this study. 